\title{
Interrenal type of abdominal aortic coarctation with unusual complications
}

\author{
M. Janíček and O. Hollmotz \\ From First Internal Department, University Hospital, \\ Palacký University, Olomouc, Czechoslovakia
}

We report the case of a patient suffering from the interrenal variety of coarctation of the abdominal aorta, with concurrent occlusion of the coeliac artery and a wide collateral originating from the inferior mesenteric artery and supplying the region of the superior mesenteric artery.

The patient had previously been submitted to right nephrectomy for kidney abscess and the remaining kidney was supplied by twin renal arteries. These were stenosed near their origin from the aorta.

$A$ bypass operation was done connecting the aortic segments above and below the coarctation site as well as an aortorenal anastomosis, the latter in order to ensure an adequate blood supply to the remaining kidney. Blood pressure became normal after the operation.

Coarctation of the aorta is usually situated above, at, or immediately below the origin of the ductus arteriosus and may be variously connected with the origin of the large vessels of the aortic arch.

Much rarer are the types of coarctation of the aorta affecting the thoracic or abdominal aortic segment, either in the shape of hypoplasia of a fairly long aortic section (according to Pyörälä et al. (1960) in about $37 \%$ ), usually congenital in origin, or the more frequent segmental type affecting sometimes simultaneously even several aortic sections (D'Abreu, Rob, and Vollmar, 1959; Glenn et al., 1952; Pyörälä et al., 1960; Zaroff et al., 1959). According to the relation to the renal artery origin, coarctation of the abdominal aorta may be subdivided into supra-, inter-, and infrarenal types (D'Abreu et al., I959; Baird, Labrosse, and Evans, 1965; Senning and Johansson, 1960).

Coarctation of the abdominal aorta was probably first described by Duncan (1843). Pyörälä et al. (1960) compiled only 27 published reports up to 1927; Baird et al. (1965) mentioned 20; Pokrovsky, Melnik, and Rushanov (1965) cited 38 cases. In contrast to coarctation of the aortic arch, a congenital origin of abdominal aortic coarctation is quite exceptional (Fisher and Corcoran, 1952; Maycock, 1937). Much more commonly an inflammatory aetiology, e.g. aortitis of unknown origin, is quoted as the cause of the disorder (Danaraj and Wong, 1959; Glenn et al., 1952; Pyörälä et al., 1960; Zaroff et al., 1959).

In view of the relative rarity of the disorder, we wish to present a report on a patient with coarctation of the abdominal aorta accompanied by further unusual complications.

\section{Case report}

The patient was a man of 22 years. He gave a history of three attacks of pneumonia up to the age of 15 years. At that age he suddenly felt overwhelming weakness of the lower limbs and was unable to walk for a month. Thereafter he suffered from intermittent claudication. In the same year he underwent right nephrectomy for renal abscess. This illness was associated with a high fever. A few days after operation arterial hypertension was discovered. The diastolic pressure persisted at a level of over $100 \mathrm{mmHg}$. Shortly before admission to the department he developed headache and shortness of breath on exertion.

Heart and lungs were normal apart from an accentuated aortic second sound. There was a grade I systolic murmur over the left carotid and subclavian arteries. A nephrectomy scar was present on the right flank, the liver was at the rib border, the spleen not palpable. There was a loud roaring systolic murmur grade 3-4 in the umbilical region. The femoral artery pulse could not be palpated. Blood pressure in the upper limbs was 180-240/110-140 mmHg. The blood pressure could not be measured in the lower limbs. The blood count and urea and electrolytes were normal. The electrocardiogram showed left ventricu- 
lar hypertrophy with strain. Chest $x$-ray showed heart size within normal limits, no congestion, and streaky marking in the right cardiophrenic angle. Isotope renography showed a missing segment on the right, and normal appearance on the left. Excretory pyelography revealed normal findings on the left, and no excretion on the right.

From the past history, physical examination, and ancillary investigations, a preliminary diagnosis of coarctation of the abdominal aorta was made and the patient was sent for aortography, using the Seldinger technique. Initially the catheter could be inserted only as far as the lower margin of $\mathrm{L}_{1}$ (Fig. I). Seriograms revealed a hypoplastic abdominal aorta extending from the upper border of $\mathrm{L}_{1}$ to the bifurcation. Massive collateral circulation was present, from the inferior mesenteric artery into the superior mesenteric artery via the left and middle colic arteries, the so-called Riolani anastomosis; moreover, there was collateral circulation through the pancreaticoduodenal arcade, in which the pancreaticoduodenal arteries and the splenic artery participated. These collateral routes indicated the presence of a central coeliac artery occlusion. A cautious attempt was made at advancing the catheter a little higher. During phase II (Fig. 2) the obstacle was successfully overcome and the catheter advanced as far as the lower border of D II. Seriograms confirmed the presence of coeliac artery occlusion and, in addition, revealed a segmental, interrenal coarctation of the aorta with stenosis of the origin of twin renal arteries on the left.

The patient was transferred to the Institute of Clinical and Experimental Surgery in Prague, and an operation was done on II November 1968 by Professor L. Hejhal.

From the operation report, access was obtained by a left thoracoabdominal incision and the lower thoracic and abdominal aorta approached. The stenosed segment of the aorta started near the coeliac artery origin and terminated between the origin of the renal arteries and the inferior mesenteric artery. The arteries in and around the stenosed area displayed gross changes of an inflammatory character. The stenosed section was excluded by thoracoabdominal aorto-aortic bypass, connecting the lower thoracic segment of the aorta to the abdominal aorta above its bifurcation with end-to-side anastomoses. The arteriographic finding of two left renal arteries was confirmed. Their internal calibre was about $3 \mathrm{~mm}$. Both branches of the left renal artery were incised laterally and joined together to form one large vessel. This was sutured end to side to the thoracoabdominal bypass. In view of the adequate collateral circulation in the superior mesenteric territory, no reconstruction of this artery was indicated. Operation and recovery were without

FIG. I First phase - lower abdominal aortography. Complete filling of left and middle colic arteries showing a bizarre pattern of coils. Rapid passage through Riolani's anastomosis into superior mesenteric artery as a result of high obliteration of the coeliac axis. Details in the text. FIG. 2 Second phase - upper abdominal aortography. Interrenal coarctation of abdominal aorta with advanced stenosis of left renal arteries. The coeliac artery failed to fill with contrast medium.

(FIG. I)
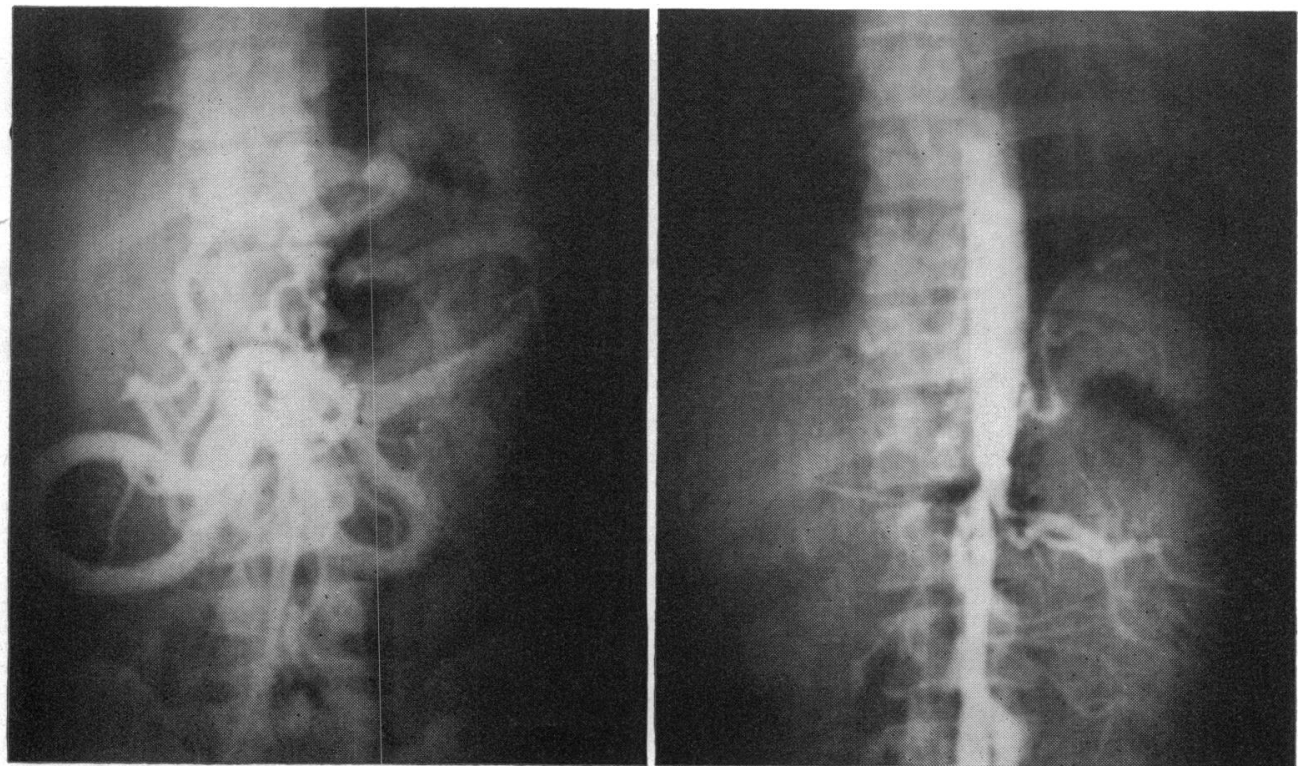
complications. The blood pressure returned to normal after the operation.

As stated in the introduction, our patient was suffering from a very rare type of interrenal coarctation of the abdominal aorta. No conclusion could be reached as to whether the disorder was congenital or acquired. Twin renal arteries on the left is such a common anomaly that it provides no support for the possible congenital aetiology. On the other hand, the sudden onset of claudication, arterial hypertension, the simultaneous presence of a kidney abscess on the opposite side, the irregular narrowing of the aortic lumen revealed by aortography as well as by operation, and the coexistent occlusion of the coeliac artery, are all in favour of an inflammatory aetiology. The fact that the patient possessed a solitary kidney which, in addition, was supplied by twin stenosed renal arteries, led to the decision to ensure adequate flow through the remaining kidney and lower aorta by a bypass operation.

The coincidence of coarctation of the abdominal aorta with occlusion of the coeliac artery and supply of the superior mesenteric artery by collaterals from the aortic segment below the occlusion is very rare. A similar case has so far been reported only by Baylin (1939).

\section{References}

Baird, R. J., Labrosse, C. J., and Evans, J. R. (1965). Coarctation of the abdominal aorta. Report of a case and review of the literature. Diseases of the Chest, 48, 517.
Baylin, G. J. (1939). Collateral circulation following an obstruction of the abdominal aorta. Anatomical Record, 75, 405.

D'Abreu, A. L., Rob, C. G., and Vollmar, J. F. (1959). Die Coarctatio aortae abdominalis. Langenbecks Archiv für klinische Chirurgie, 290, 521.

Danaraj, T. J., and Wong, Hee Ong (1959). Primary arteritis of abdominal aorta in children causing bilateral stenosis of renal arteries and hypertension. Circulation, 20, 856.

Duncan, J. (1843). Case of spontaneous obliteration of the aorta. The London and Edinburgh Monthly fournal of Medical Science, 3, 781.

Fisher, E. R., and Corcoran, A. C. (1952). Congenital coarctation of the abdominal aorta with resultant renal hypertension. Archives of Internal Medicine, 89, 943.

Glenn, F., Keefer, E. B. C., Speer, D. S., and Dotter, C. T. (1952). Coarctation of the lower thoracic and abdominal aorta immediately proximal to celiac axis. Surgery, Gynecology and Obstetrics, 94, 561.

Maycock, W. d'A. (1937). Congenital stenosis of abdominal aorta. American Heart fournal, 13, 633.

Pokrovsky, A. V., Melnik, I. Z., and Rushanov, I. I. (1965). Koarktacija brušnoj aorty (English summary). Khirurgiya, 41, no. 5, p. 127.

Pyörälä, K., Heinonen, O., Koskelo, P., and Heikel, P. E. (1960). Coarctation of the abdominal aorta. Review of 27 cases. American fournal of Cardiology, 6, 650.

Senning, A., and Johansson, L. (1960). Coarctation of the abdominal aorta. Fournal of Thoracic and Cardiovascular Surgery, 40, 517.

Zaroff, L. I., Kreel, I., Sobel, H. J., and Baronofsky, I. D. (1959). Multiple and infraductal coarctations of the aorta. Circulation, 20, 910. 